\title{
Incidencia de los medios de comunicación en el desarrollo de la identidad cultural en comunitarios y comunitarias, Wasakín, Municipio de Rosita 2015-2016
}

\author{
The media incidence in the development of cultural identity in communitarians, \\ Wasakín, Rosita Municipality 2015-2016
}

Lázaro Ramón Figueroa Reyes ${ }^{1}$ Jacoba del Carmen Dávila Molina²

\section{Resumen}

Utilizando la metodología del CCRISAC, la investigación se realizó en la comunidad de Wasakin, a través de un proceso de convivencia con ancianos, ancianas, líderes y lideresas. El contexto sociocultural en que viven comunitarios y comunitarias, muestran que las costumbres y tradiciones han cambiado con el pasar de los años, desde las formas de organización y gobernanza territorial, respeto por las autoridades comunales así como la sustitución de su lengua materna sumu-tuahka por el miskitu. El estudio constata que la televisión responde a un perfil comercial y a una programación transmitida en español e ingles, y por ende, a una cultura distinta al de los pueblos indígenas. Son medios de comunicación que han penetrado el tejido social, logrando incidir en las formas de vida, prácticas y actitudes de las personas que la ven. Tanto la televisión como la radio rompieron esquemas y se incorporaron a la vida cotidiana familiar del territorio. Particulamente, llama la atención que la televisión se ha convertido en parte importante de la cultura, al constatarse que las imágenes alteran las emociones y los espacios de las personas, estimulan las narrativas orales y visuales y, transforman las prácticas culturales de la comunidad.

Palabras clave: Desarrollo con identidad; wasakín; cultura; lengua; convivencia; trans-culturalización.

\section{Abstract}

By using the CCRISAC methodology, the research was carried out in Wasakin community, through a process of coexistence with the elderly and community leaders. The sociocultural context in which communitarians live, show that customs and traditions have changed over the years, from the forms of territorial organization

\footnotetext{
1 Máster en Comunicación Intercultural con Enfoque de Género. Lic. en Comunicación Intercultural. Director de Radio URACCAN Rosita. E:mail: figueroareyes4@gmail.com

2 Doctora en Educación con especialidad en Mediación Pedagógica. Msp. en Salud Intercultural. Coordinadora del Centro de Estudios e Información de la Mujer Multiétnica, CEIMM, URACCAN Siuna. E-mail: jacoba2013@gmail.com
}

Recibido: 26/02/2018 Aprobado: 28/o8/2018

Figueroa-Reyes, L., \& Dávila-Molina, J. (2018). Incidencia de los medios de comunicación en el desarrollo de la identidad cultural en comunitarios y comunitarias, Wasakín, Municipio de Rosita 2015-2016. Ciencia E Interculturalidad, 23(2), 70-85. D0l: https://doi. org/10.5377/rci.v23i2.6569 
and governance, respect for the communal authorities as well as the substitution of their mother tongue sumu-tuahka for the miskitu. The study confirms that televisión responds to a commercial profile and TV programming transmitted in Spanish and English, and therefore, to a culture different from that of indigenous peoples. They are means of communication that have penetrated the social fabric, making an impact on the ways of life, practices and attitudes of the people who watch them. Both televisión and radio broke schemes and were incorporated into the familiar daily life of the territory. Particularly, it is striking that televisión has become an important part of culture, as it is observed that images alter people's emotions and spaces, stimulate oral and visual narratives and transform the cultural practices of the community.

Keywords: Identity development; wasakín; culture; mother tongue; coexistence; transculturalization.

\section{Introducción}

La presente investigación aborda la incidencia que tienen los medios de comunicación en el desarrollo de la identidad cultural de comunitarios y comunitarias, realizada en la comunidad indígena sumu-mayangna tuahka del Municipio de Rosita Región Autónoma de la Costa Caribe Norte de Nicaragua (RACCN). Se destaca como aspectos claves el contexto sociocultural en el que conviven, los factores que inciden en el desarrollo de la identidad cultural y de manera conjunta con la comunidad, proponer acciones que contribuyan al rescate de la identidad cultural.

Es claro que los medios de comunicación con su avance tecnológico se han incorporado en las culturas indígenas sirviendo como intermediario de una relación de conocimiento globalizado en diferentes paradigmas como en el impulso de la destrucción de la cultura, esto ha cambiado el pensamiento propio de su cosmovisión. Por consiguiente, fortalecen referentes de identidad, se reproducen representaciones sociales, se afianzan valores, principios de relación, se construye una opinión frente a los asuntos de interés nacional estos pueden ser a favor o en contra de las diferentes culturas según el origen de cada pueblo, es por ello la importancia de esta investigación.

Para el pueblo indígena sumu-mayangna tuahka resulta fundamental defender su cultura, considerándola parte importante de su existencia e integridad que ha sido trasmitida de generación en generación, es por eso la necesidad de accionar planes que contribuyan al rescate de la identidad y por ende la cultura del pueblo sumumayangna tuahka de wasakin. 


\section{Revisión de literatura}

\section{Contexto sociocultural en que vive la población}

De acuerdo a Fonseca y Escribano (2009, p.74), la gobernanza territorial indígena se expresa en el pleno ejercicio de la autonomía, (...) es cuando las autoridades comunales y territoriales desempeñan un papel fundamental en el proceso ya que, en conjunto con los líderes territoriales, establecen la planificación e implementación del sistema de autonomía territorial dentro y hacia afuera de los territorios.

Siguiendo a Acosta (2004), tanto el derecho a la propiedad sobre los territorios comunales tradicionales, como el derecho consuetudinario de los pueblos indígenas de la Costa Caribe de Nicaragua se encuentran reconocidos por la Constitución Política y el Estatuto de Autonomía de las Regiones de la Costa Caribe de Nicaragua, estas normas no han tenido el desarrollo necesario y efectivo para proteger a los pueblos ante las sistemáticas prácticas de usurpación realizadas por particulares. Esta usurpación se concreta en la imposición del derecho escrito, por sobre los usos y las formas de tenencia de tierras tradicionales, que forman parte del derecho consuetudinario de estos pueblos.

Desde la perspectiva de Cunningham (2010), entendemos a las autoridades comunales, en este caso, el Consejo de Ancianos, como una entidad colegiada de consulta, formada por ancianos líderes que por su experiencia y sabiduría aconsejan y orientan a las otras autoridades que en algún momento, también forman parte del proceso y efectividad del derecho consuetudinario.

En tiempos pasados el castigo de los criminales era confiado a la persona agraviada, más que a oficiales especiales de justicia, se infligían castigos en formas de multas azotes y muerte, en dependencia del delito cometido (Conzemius, 2004).

En este contexto y siguiendo la lógica de Gómez (2010), la iglesia morava también habría desempeñado predominancia en el desplazamiento de la lengua sumu. El hecho de usarla como medio para cristianizarlos provocó un fuerte impacto, asi como la traducción de la biblia al miskitu por los moravos. Asimismo, el uso de la lengua en las ceremonias religiosas marcaba categorías de valor diferenciado donde el miskitu se hablaba y se escribía a la vez, mientras el sumu, solamente era hablado.

\section{Factores que inciden en el desarrollo de la identidad cultural de la población desde los medios de comunicación}

Hoy en día la mayoría de la juventud adoptan modelos reforzados desde los medios de comunicación debido a que en el entorno que tienen, llámese familia, colegio y sociedad en general, no encuentran patrones con los que se sientan realmente identificados e 
identificadas, por lo que estos modelos, aunque sean irreales, los adquieren a través de los medios, sin que nadie les cuestione la validez o no de ellos, ni se les inculque que son irreales y creados, que lo que luego se van a encontrar en la realidad no se corresponde con los que están creando, con lo que muchos jóvenes viven en un mundo parcialmente irreal (Liceras, 2005, p.4).

Tornero y Parcerval (s.f), argumentan que la televisión con su enorme poder de difusión y con su capacidad para fascinar a las audiencias, tiene un impacto decisivo en la consolidación de los usos lingüísticos. Los espectadores tienden a asimilar tanto las formas como los contenidos de los usos lingüísticos y a hacerlos suyos progresivamente. De este modo, conscientes o no, las normas que sigue la televisión en materia de usos lingüísticos acaban influenciando y configurando las pautas de los hablantes que conforman su público.

\section{Acciones que contribuyan al rescate de la identidad cultural.}

La comunicación y los medios son clave para la sensibilización, el intercambio de conocimientos y el apoyo a un debate más amplio sobre los saberes, la cultura y los valores indígenas. De acuerdo a Ban Ki-moon (2013), la combinación de todos estos aspectos conduce a políticas y planes de acción más eficaces. Desde esta postura, la comunicación debería ser articulada primeramente entre miembros de una misma cultura, con códigos y significados comprensibles desde la complejidad de los símbolos que usa un determinado pueblo. En este caso, destaca la importancia de de que sean los propios pueblos indígenas los que trabajen la comunicación en el desarrollo (Plaza, 2014).

Finalmente, se hace oportuno decir: "De la radio a la televisión comunitaria, al cine y a los documentales, al video arte y a los diarios, a internet y a los medios sociales, los pueblos indígenas están utilizando estas herramientas poderosas para desafiar los discursos hegemónicos y llevar a un plano internacional de discusión la violación de los derechos humanos, forjando así una solidaridad global”. (Ban Ki-moon, 2013).

\section{Materiales y métodos}

La investigación se realizó en la comunidad de Wasakin con la metodología del CRISAC, que consistió en la convivencia con la comunidad, lo que permitió observar los problemas o dificultades para darle salida a los mismos. Ayudó a descubrir detalles que no se pueden visibilizar a simple vista, asimismo conocer realidades útiles para fundamentar las vivencias de los pueblos que se sienten identificados cuando se toma en cuenta su participación.

El proceso se realizó a través de técnicas participativas que están planteadas como esenciales dentro de las señaladas como formas de cultivo y crianza de sabidurías 
y conocimientos, entre ellas: rastreo etimológico, conversatorios, convivencias y observación participante que permite la sistematización de sabidurías y prácticas.

Posterior a la aplicación de las técnicas se procedió con la información recopilada, al procesamiento de la misma. Como parte fundamental del proceso de investigación se compartió con las y los comunitarios los resultados y la propuesta del CCRISAC, para validar y solicitar el aval de la investigación.

\section{Resultados y discusión}

\section{Contexto sociocultural en que vive la población de Wasakin del municipio de Rosita}

El contexto sociocultural en que viven comunitarios y comunitarias, muestran que las costumbres y tradiciones han cambiado con el pasar de los años, desde las formas de organización y gobernanza territorial, respeto por las autoridades comunales así como la sustitución de su lengua materna sumu-tuahka por el miskitu.

Por medio de la observación se constató que la comunidad de Wasakin tiene una diversidad étnica. Habitan personas hablantes tuahka, miskitu y español; cada día la población va creciendo en la comunidad, a la vez más se mezclan y van dejando de practicar su lengua materna y por lo tanto su identidad está en crisis, las nuevas generaciones no son meramente sumu-mayangna, ya son mezclados con miskitu o mestizos y ellos deciden como se quieren identificar y que costumbres adoptar.

Este territorio está resguardado bajo el régimen de propiedad comunal de los pueblos indígenas y comunidades étnicas, mejor conocida como la Ley 445, y hay muchos que desconocen la ley. Paralelo a ello, existen problemas con la invasión de colonos y la venta ilegal del territorio. Todo está cambiando, ya no tenemos armonía para dialogar con los ancianos o con las autoridades porque todos piensan que si nos reunimos es para vender las tierras comunales, siento que estamos perdiendo nuestros espacios para dialogar y de comunicarnos (B. Fenlis, comunicación personal, o4 de agosto del 2016).

A diferencia con lo planteado por Fonseca y Escribano (2009), manifiestan que las autoridades comunales y territoriales desempeñan un papel fundamental, en conjunto con líderes territoriales, establecen la planificación e implementación del sistema de autonomía territorial dentro y fuera de los territorios.

Tanto el derecho a la propiedad sobre los territorios comunales tradicionales, como el derecho consuetudinario de los pueblos indígenas de la Costa Caribe de Nicaragua están reconocidos por la Constitución Política y el Estatuto de Autonomía. Estas normas no han tenido el desarrollo efectivo para proteger a los pueblos ante 
las sistemáticas prácticas de usurpación realizadas por particulares, realizada por medio de la imposición del derecho escrito, por usos y formas de tenencia de tierras tradicionales, que forman parte de este derecho (Acosta, 2004).

Consistente con la legislación nacional, los territorios indígenas no se pueden vender, ni arrendar, son territorios comunales para el goce de sus habitantes. Los problemas de tierra que enfrenta la comunidad de Wasakin no son por desconocimiento de ley de habitantes y personas ajenas al territorio, ya que la divulgación de las leyes que velan por los territorios indígenas se dan a conocer en los medios de comunicación radiales.

Al respecto, las personas involucradas en esta investigación refirieron: las formas tradicionales de organización han variado en comparación con las formas de organización actual, antes la dirección del pueblo Sumu estaba regido solamente por tres instancias, el consejo de ancianos, sindiku, wihta y pastor, en cambio actualmente existe otras formas de organización como es el sindiku, consejo de ancianos, wihta, pastor, profesor, líder de salud, consejo escolar organización de mujeres, organización de jóvenes y el gobierno territorial.

N. Melado (comunicación personal, 27 de julio del 2016), explica que:

Las personas mayores tenían el pensamiento de unidad, platicaban, meditaban, consensuaban y se sometía a la elección como su dirigente, así se elegían a quien poner como su líder, el que resultaba electo gobernaba por un lapso de tiempo. Por otra parte el papel que desempañaba el sindiku, se basaba en la defensa de su comunidad, bienestar de sus habitantes, a través de la historia es la persona que orienta a hacer cumplir la norma de la comunidad Sumu tuahka.

Según F. Gómez, actualmente la juventud, es la que ha tomado el poder para elegir a los representantes del pueblo, omitiendo el poder ancestral, "porque durante las elecciones no se da la participación a los ancianos en opinar como ancianos de autoridad». (Comunicación personal, 10 de agosto del 2016).

Existe la necesidad de rescatar la cultura comunal del pueblo Sumu Tuahka, porque el problema del liderazgo actual no vela por los intereses de la población. Para F. Gómez: «velar por los intereses familiares; es el modelo de líder comunal actualmente. El Poder del sindiku es una imagen económica por tener ese valor de jerarquía con los empresarios, autoridades, políticos y la sociedad» (comunicación personal, 10 de agosto del 2016).

Cunningham (2010) al respecto señala al Consejo de Ancianos como una entidad colegiada de consulta, formada por ancianos, ancianas líderes que por su experiencia, 
sabiduría aconsejan y orientan a las otras autoridades, existiendo esta parte primordial en la organización indígena.

La cultura del pueblo de Wasakin ha existido durante muchos años y es en esta época globalizada que surgen cambios en todos los entornos hasta el extremo de llegar a irrespetar lo que tradicionalmente se practicaba, donde los ancianos son los más indicados en la toma de decisiones por su experiencia, sabiduría, derecho de haber vivido más tiempo y conocer el territorio.

Los sabios consejos de los ancianos mantuvieron unido por años a la población, hoy se reflejan conflictos entre las familias, personas ajenas a la comunidad por un mal gobierno comunal ejercido sin experiencia y conocimiento expresan los ancianos de la comunidad.

La población refleja que las normas tradicionales, costumbres y cosmovisiónes se han dejado de practicar y desvalorizar, porque la nueva generación se ha apropiado de culturas exógenas por la incidencia negativa de la política, la globalización y medios de comunicación.

N. Melado (comunicación personal, 27 de julio del 2016), compartió un ejemplo: En tiempo anteriores la comunidad tenía sus propias normas de cómo aplicar sanciones de acuerdo a las categorías de los delitos cometidos, en aquel entonces no había cárcel, pero se castigaba con el rechazo moral y social tanto de la sociedad como de la iglesia, este rechazo alcanzaba a la familia de los involucrados, existiendo como uno de los castigos más importantes, entre otros que se tenía.

En tiempos pasados el castigo de los criminales era confiado a la persona agraviada, más que oficiales especiales de justicia, se infligían castigos en formas de multas azotes y muerte, esto iba en dependencia del delito cometido (Conzemius, 2004). Para muchas personas los castigos y sanciones en tiempos pasados eran consideradas extremas en algunos casos, la comunidad no tenía tantos problemas como los tiene hoy, se respetaba la palabra de las autoridades, todos veían las leyes de la comunidad como verdaderas normas de convivencias, por temor a no romperlas a ser castigados las cosas surgían bien. Hoy, las leyes muchas veces no son justas y se quedan sin castigos por los delitos cometidos.

La religión que profesan es la Morava en su mayoría desde 1980 y una minoría asiste a la Iglesia Maranata, los cultos en ambas Iglesias son realizados en lengua miskitu, una lengua ajena que han venido adoptando comunitarios y comunitarias de Wasakin. Lo expresado, coincide con Gómez (2010), al expresar que la iglesia Morava, ha desempeñado predominancia en el desplazamiento de la lengua sumu. El hecho de usarla como medio para cristianizar a los sumu mayangnas tuvo fuerte impacto por el hecho de que la Biblia la tradujeron en lengua miskitu los Moravos. Esto, y el hecho de 
usar la lengua en las ceremonias religiosas marcaba categorías de valor diferenciado: el miskitu era una lengua importante y escrita, el sumu solamente hablada.

Por otro lado P. Fenlis (comunicación personal, o3 de agosto del 2016), expresa: antes la prédica en la religión Morava era en miskito y Tuahka, ahora es en tres idiomas esto viene a afectar nuestra cultura, estamos siendo invadidos por otros idiomas, ejemplo el miskito se habla más que el Tuahka y ahora los jóvenes practican más el español, y en nuestros sitios de adoración a Dios, nos hablan en tres idiomas cuando debería de ser en Tuahka que es nuestra identidad, ahora no solo los medios de comunicación contribuyen a que adoptemos el español sino que los pastores en las iglesias nos hablan así también.

La religión ocupa un espacio muy importante para el pueblo de Wasakin. Por tradición las familias siempre han estado inmersas en las cosas de Dios y su cultura está basada en una vida de armonía, paz con la naturaleza y la espiritualidad. Lo que demuestra que las diferentes denominaciones religiosas ejercen un papel primordial en la vida de las personas. La mayoría de comunitarios y comunitarias de Wasakin visitan la iglesia Morava y en una minoría la Maranata. Ambas tienen una forma diferente de honrar, pero tienen algo en común, su prédica, himnarios y lecturas bíblicas es en idioma miskitu, lo que impide el fortalecimiento de la identidad cultural del pueblo sumo Tuahka, ya que desde la religión se impone la lengua miskitu. Es evidente que la feligresía sumo-tuahka ha adoptado el miskitu como primera lengua en detrimento de la identidad propia y la lengua.

De igual manera, en medios de comunicación como radio, las prédicas en su mayoría las transmiten en lengua miskitu, raras veces en tuahka, lo que demuestra que también en estos espacios radiales la utilización del idioma miskitu está por encima del propio. A pesar de que comunitarios y comunitarias están conscientes del hecho de que su prédica, himnos y cantos deberían ser en su lengua materna sumu-tuahka hasta el momento no se han hecho acciones que promuevan la revitalización y rescate de su lengua en la iglesia.

\section{Factores que inciden en el desarrollo de la identidad cultural de la población desde los medios de comunicación}

Entre los principales factores que inciden en la identidad cultural, se presentan: el avance tecnológico con ello la energía eléctrica, los medios de comunicación radiales y televisivos, sumado a ello la migración de personas de otras etnias a la comunidad.

Según ancianos para ellos eso no era un factor fundamental, el contar con energía eléctrica, ya que por años han sobrevivido sin ella y eso vino a destruir la cultura ancestral, al respecto un comunitario refirió: Mis abuelos me decían que ellos no necesitaban la energía eléctrica, porque nuestra luz está en el pino con eso nos hemos 
alumbrado siempre, antes hacíamos una fogatas para reunir a la comunidad y compartir las leyendas, cuentos y costumbres, hoy en día esto no se hace, a los ancianos no se les toma en cuenta, ahora se le cree más lo que dice la televisión y la Radio estos nuevos avances están terminado con la identidad de nuestro pueblo, estamos perdiendo nuestra identidad (R. Poveda, comunicación personal, o2 de agosto del 2016).

Lo mencionado anteriormente se relaciona con lo que expresa Licera Ruíz (2005) citando a Díaz (2005): Los medios de comunicación se han convertido en el corazón de la vida política y cultural, componiendo la imagen de la realidad que van a trasmitir, esto hace que sus receptores vayan integrando como propia, lo que determina que todo lo que ven, escuchan y leen a través de la televisión, la prensa, la música y las nuevas tecnologías corren el riesgo de convertirse en un poderoso instrumento de manipulación y alineación social, la televisión ha creado comunidades visuales, figuras del mal, violencia, horror, catástrofe, accidentes que introduce lo real en estado bruto. (p.4)

Comunitarios y comunitarias refirieron que en vez de practicar su cultura ahora van avanzando como lo hacen otras culturas, cuentan con luz eléctrica, la nueva generación camina con los radios escuchando música de Lucky Dube y las personas ahora ven más televisión y no existe ese espacio de convivencia, antes lo que hacían era fogata con leña de pino para compartir con las mujeres, jóvenes y niños.

Consideran que la juventud es la que más está practicando las culturas de otro lado, escuchando otro tipo de música no interpretan los pocos cantos que existen en tuahka, ahora se ven por la comunidad a jóvenes con celular escuchando música, chateando, adoptando otra cultura ajena a la de del pueblo, la tradición de reuniones entre comunitarios y comunitarias se ha dejado de practicar, las oratorias familiares, los hijos no dialogan con sus padres por estar con sus radios o televisores, expresaron algunos comunitarios.

Desde el momento que la tecnología invadió la comunidad de Wasakin se han visto grandes cambios, por tradiciones los pueblos indígenas no dependía de energía eléctrica, mucho menos de medios de comunicación, contaban con sus propios recursos para comunicarse con sonidos y el compartimiento de la información se hacían en asambleas o conversatorios familiares.

Durante las observaciones en el periodo que duro el contacto con la comunidad, fue evidente el hecho de ver como los miembros de las familias especialmente los más jóvenes dedican tanto tiempo a la televisión o a escuchar todo el tiempo la radio, olvidándose del compartir un tiempo con sus familiares y conversar sobre sus cosas.

Un anciano comparte: Yo veo programas en la televisión aunque el idioma es en español o en inglés, porque en la televisión no hay indígenas, en la radio si hay, cuando está el programa voces y cuerdas de Radio Stereo Jesús ahí hablan en tuahka, en 
miskito y español y eso si lo entendemos bien, cuando escucho el programa del IPILC en Radio URACCAN es importante porque nos habla de los derechos de los pueblos indígenas pero a veces el mensaje no se interpreta bien porque se mezcla la lengua Tuahka con el Panamahka y muy pocos entendemos esos otros idiomas. (W. Penn, comunicación personal 4 de agosto del 2016).

Los medios de comunicación tienen un impacto positivos en la consolidación de los usos lingüísticos; tal como lo afirman Tornero y Parcerval (s.f) al expresar que los espectadores tienden a asimilar tanto las formas como los contenidos de los usos lingüísticos y hacerlos suyos progresivamente y que el enriquecer o corromper un lenguaje es una influencia posibles en los usos lingüísticos de una comunidad.

El lenguaje que se utiliza en los diferentes medios de comunicación es importantes para los pueblos indígenas porque les permite estar en comunicarse con el resto de poblaciones, siendo para ellos una segunda lengua (L2), con la cual obtienen mayores oportunidades en el ámbito laboral y social puesto que la mayor población en todo el municipio es mestizo y ellos necesitan comunicarse para suplir diferentes necesidades que dependen de este grupo poblacional.

No obstante es importante señalar que los medios de comunicación ofrecen programación en español contribuyen a enriquecer sus conocimientos, pero interfieren en el proceso lingüístico nativo a como lo es el sumu-tuahka, sustituyendo así su propia lengua por el uso excesivo de otras lenguas. Los medios de comunicación radiales de la región son únicos que tienen algunos programas en lenguas tuahka, deberían de contar con mayor programación con los cuales se sientan identificados comunitarios y comunitarias de Wasakin no solo por su significado, sino por el mensaje que es trasmitido en su lengua nativa, proporcionando mejor comprensión de los contenidos y respeto al derecho de la lengua estipulado en la ley de lengua.

Lo anteriormente descrito, se fundamenta en la Ley de Lengua, Ley 162 (Asamblea Nacional, 1993), y que en su artículo 10, establece la responsabilidad social que tienen los medios de comunicación nacionales y regionales en fomentar desde su programación, el uso de las lenguas de las comunidades de la Costa Caribe. Por consiguiente, deberán articular sus programas promoviendo la riqueza y la diversidad cultural de la nación.

La televisión en sus diferentes programas ofrece un mundo lleno de esperanzas, oportunidades, niveles de vidas extraordinarias, hechos presentados en las novelas, películas, series, caricaturas, noticias entre otros programas que asemejan una realidad imaginaria, llamando la atención de cada uno de sus televidentes quienes poco a poco se sienten atraídos e identificados con los contenidos trasmitidos e impulsa a muchos a buscar una vida igual a lo visto. 
Para ancianos y ancianas de esta comunidad, es un proceso complejo que va más allá de querer o no ser igual a otros personajes vistos en la televisión, se trata de su identidad cultural, de la riqueza que poseen como pueblo indígena, su vivencia y cosmovisión, cosas no palpables pero si reconocidas, las cuales poco a poco van en decadencia tanto que hay pueblos que han perdido por completo su cultura debido al proceso de trans-culturalización al que están expuestos con la incidencia directa de medios de comunicación que no están dirigidos específicamente a comunidades indígenas para lograr la revitalización cultural. Los medios de comunicación son buenos, pero no es parte de nuestra cultura argumenta Gómez Escobar (Comunicación personal, 10 de agosto del 2016).

La televisión es muy bonita, pero tiene ventajas y desventajas para la identidad propia, la ventaja es que se aprende muchas cosas, desventajas es que se deja la cultura propia y se adopta la cultura ajena, a través de la televisión los jóvenes miran y quieren adaptarse a lo que hacen los jóvenes de los países potenciales, su forma de vestir, su forma de actuar, entonces deja su propia cultura y está adaptándose a una cultura ajena.

Hoy en día en la televisión está afectando más a los jóvenes continuó relatando Gómez Escobar (comunicación personal, 10 de agosto del 2016). «Las y los jóvenes miran las telenovelas y esto afecta la cultura quieren pasar viendo día y noche, afecta en el hogar ya no hacen los quehaceres, los niños quieren pasar todo el tiempo viendo caricaturas y ni comer quieren». El uso desmedido y sin control de los medios de comunicación televisivos afecta el rol de cada miembro de la familia así mismo interfiere en su espacio y tiempo cuando son más dedicados a ver televisión, llenándose de un mundo con actuaciones y estilos de vidas ajenos a su cultura.

Nuestro entrevistado compartió parte de una conversación surgida con su mamá donde comentó: Los mayores usaban la vestimenta de colores, mi mamá de 70 años de edad cuando vio las noticias en tele Sur se conmovió y me dijo hijo esos bailes son de pavo real y esos colores con la vestimentas lo practicaban mis abuelitos, me comentó mi mamá.

Las personas que formaron parte de este proceso investigativo reflejan que su pueblo ha adoptado cultura de otros, hasta en las formas de vestirse, los varones andan de pantalones socados, camisas de marcas, zapatos modernos. Las mujeres mayangnas no utilizaban pantalones, con la transculturización usan el pantalón, hasta a la iglesia se va en pantalón, se pintan, usan blusas con escotes, faldas chingas que descubren sus rodillas y llenas de prendas de oro, plata y acero, cuando antes los collares y chapas eran artesanales hechos en la comunidad, pero como en la televisión se ve cómo avanza la moda, todos quieren ser igual y vestir con lo nuevo. 
Se pudo observar como las personas, especialmente la juventud muestra estos cambios en sus vestimentas y comportamientos, las prendas de vestir utilizadas no son iguales a la de sus ancestros, sino más bien están a la moda tanto que ahora cuesta encontrarse a las muchachas con faldas largas, ya no conservan su belleza en los cabellos largos y brillantes que se acostumbraba ver en las mujeres indígenas, ahora utilizan diferentes cortes de pelo modernos, se pinta el cabello en rojo, amarillo y otros con múltiples colores.

Los medios de comunicación con su afán de vender publicidad presentan cambios constantes en las diferentes actividades relacionadas con la población, ofreciendo productos, trabajos y formas de vida diferentes y con una buena promoción logran contagiar a las personas para querer asemejar su actuar con el presentado en la televisión.

La moda mostrada en cada publicidad que vende los diferentes medios de comunicación han influidos directamente en la pérdida de la identidad cultural y refleja un obstáculo grande para el rescate de su cultura, los jóvenes se visten y actúan diferentes, ya no utilizan los atuendos que caracterizaba a los adultos indígenas.

Al respecto J. Cruz Meléndez (comunicación personal, agosto del 2016), comunica que las prácticas culturales en la comunidad se han perdido: Una de nuestras tradiciones era pedir la mano de la muchacha para casarte con ella, pero para lograrlo existían cinco formas, ahora a los jóvenes no les interesan esas normas o tradiciones simplemente actúan como en las novelas o películas se lleven a la muchacha, la embarazan y la dejan por otra, esto no es de nuestra cultura, las mujeres eran reconocidas como esposas para toda la vida.

N. Melado originario de Wasakin muestra su preocupación por la incidencia que están teniendo los medios de comunicación televisivos en la población de Wasakin quién refiere que hoy en día los jóvenes ven la televisión y actúan como en las películas y las novelas, se roban a las muchachas y las abandonan embarazadas o con el montón de hijos e hijas sin responsabilidad alguna. Melado (comunicación personal, 30 de julio del 2016).

No es fácil establecer juicios o reflexiones en torno a estos abordajes o resultados propios que son parte de las vivencias o prácticas culturales de un pueblo ancestral. Por el hecho de vivir en una región con características interculturales donde se promueve el respeto a la identidad de los pueblos indígenas tal como se establecen en varios instrumentos jurídicos como la Ley 28 (Ley de Autonomía), la Constitución Política de Nicaragua.

Desde el punto de vista humanista, la aplicación de castigos corporales violenta la integridad física y psicológica de las personas, son penadas en procesos judiciales, por esa razón no se debe de fomentar el rescate de esas prácticas ancestrales, sino por 
el contrario se deben promover los derechos humanos de las personas, permitiendo principalmente a las mujeres el derecho de elegir libremente a las personas con las cuales van a compartir y formar sus propias familias, respetando sus etapas de crecimiento.

La incidencia directa de los medios de comunicación televisivos está reflejada en las expresiones de las y los entrevistados, Así mismo es notorio ver como cada día hay niños y niñas que crecen sin padres en la comunidad, al momento de realizar las entrevistas se encontró con cuatro jóvenes que tienen hijos, no cuentan con el apoyo del padre y reflejan que los compañeros manifestaban que hasta en los grandes países y actores famosos se dejan, abandonan a sus hijos y que ellos no van a tener derechos a buscar otras mujeres si a ellas ya no las quiere.

El hecho de no responder en el hogar como padres responsables afecta principalmente a sus hijos e hijas, van creciendo sin el amor y apoyo paternal así como también se van creciendo con otros valores, la historia ha mostrado que la unidad familiar ha sido siempre característica de los pueblos indígenas y que para ellos la familia es sagrada la cual debe cuidarse y velar siempre por el bienestar, siendo el papá y la mamá unidos los que tienen la obligación de proveer alimentación, salud y educación a los hijos. Es lamentable el hecho de que los medios de comunicación televisivos y algunos radiales, no trasmitan el mensaje de armonía y valores familiares en cambio las programaciones más presentadas son de conflictos, muertes, narcotráficos y violencias.

Los resultados demuestran que aunque por historia la unidad familiar es esencial, en las realidades vividas en la comunidad de Wasakin, hay casos en la que los padres de familia no asumen sus responsabilidades en el crecimiento y desarrollo integral de sus hijos e hijas, por lo que las madres se han visto obligadas a asumir las responsabilidades para garantizar el apoyo a sus pequeños , pequeñas y en otras circunstancias los medios de comunicación influyen en múltiples cosas dentro de una cultura, una de ellas es la gastronomía la cual refleja una característica distintiva de culturas por sus sabrosos platillos típicos, la cual también ha sido influenciada por los medios de comunicación, variando los productos consumidos por tradición. Cuando se habla de gastronomía de los pueblos indígenas, es hacer referencia a las prácticas culturales alimentarias de los pueblos argumenta Melado (comunicación personal, 30 de julio del 2016).

Se está perdiendo la cultura, ya no se toman las bebidas típicas por ejemplo el wabul este era infaltable en el hogar a cualquier hora del día, ahora solo se toma por casualidad, otra bebida era el guarapo extraído de la caña de azúcar, y no se diga el pescado asado o en sopa, pero estas prácticas se están perdiendo, en mi familia lo practicamos pero no es todo el tiempo, hoy en día las jóvenes quieren comer lo que sale en la televisión y luego vamos a la venta y compramos porque ya no practicamos la caza y la pesca, es preocupante estamos en un mundo diferente, donde los medios nos hacen consumistas. 
Durante las observaciones realizadas en la comunidad se pudo notar que la comida de las personas de Wasakin ha variado en comparación con sus costumbres, toman frescos hechos de tang o productos enlatados, comen pollo importado, embutidos, pan, gaseosas, entre otros. La comunidad ha perdido su tradición de trueques o intercambios de productos, existen ventas en la comunidad donde venden productos básicos pero también productos de bisuterías, vanidades y cosméticos, hasta licor y cigarrillos. Se observaron a jóvenes comprando gaseosas con chiverías y se sientan en el corredor de la venta a ver el partido de futbol en un día domingo, cuando se supone que por costumbres todos deberían estar reunidos en la iglesia.

Se observó a dos jóvenes comprando shampoo de marca como Head shoulder y Dove, que son presentados en la televisión y no los elaborados de los recursos de la comunidad a como era antes con el jabón y los shampoo hechos a bases de hierbas para dar brillo, alarga el cabello y fortalecer el cráneo.

Antes no existían venta en la comunidad, todo era un intercambio entre familias, si una familia no tenía una cosa la regalaban o cambiaban por otra, ahora no, si no tiene dinero para comprarla no la obtiene. Todo lo que se consumía era producido en la misma comunidad, nadie necesitaba tener un trabajo con salario fijo en el pueblo, la tierra producía lo necesario para alimentarse y sobrevivir.

Las radios y principalmente la televisión están mostrando formas de trabajo diferentes que les deje ganancia en efectivo, se ve en las novelas y películas que ahora las mujeres salen a fiestas, se prostituyen por dinero, consumen alcohol (guaro), usan drogas al igual que los varones, por eso hay tantas consecuencias también mencionaron. Por querer hacer todo lo que se ve y escucha en los diferentes medios de comunicación el nivel y calidad de vida de comunitarios y comunitarias ha variado en gran manera, antes no padecían de enfermedades graves, "si acaso de dolores que eran aliviados con plantas medicinales nadie iba a los hospitales, las mujeres tenían a sus hijos en casa y las familias eran numerosas".

Las entrevistas reflejan que la adopción de las practica globalizadas han enviado al olvido lo propio, algo muy importante que compartieron es que los ancianos no iban al hospital por enfermedad de la presión o cáncer, las mujeres no iban a dar a luz al hospital, las prácticas de alimentación y medicina tradicional mantenían con buena salud a los ancianos y sin costo alguno.

Para Melado: Hoy en día hay muchas enfermedades, como el cáncer y la presión arterial, la alimentación que tenían nuestros ancianos nosotros ya no la utilizamos, me da pena decirlo pero eso así es, otra cosa es de suma importancia decirlo, la alimentación ayudaba a tener una buena salud, mis padres no padecían de presión arterial todo lo que comían y bebían era natural, sin químicos, ahora todos los indígenas padecemos 
de cáncer, presión arterial descontrolada, diabetes, esto por la alimentación ahora solo tomamos gaseosa, comemos pollo y productos enlatados.

Es indiscutible que más allá del poder que se les atribuya a los medios de comunicación, éstos han producido una rebelión en el público, puesto que lo trasmitido en cada programa no sólo influye en el momento en que se ven o escuchan, sino que su presencia se alarga en los distintos espacios de la vida social, hasta llegar a convertirse en una práctica más frecuente con la cual conlleva a que se olviden las propias por tradición.

\section{Conclusiones}

El presente proceso de análisis realizado en el contexto de este estudio, nos llevó a crear una propuesta que conlleve al rescate de la identidad cultural de la población mayangna de Wasakín desde los medios de comunicación. Con esta idea se pretende promover e incentivar desde el ámbito comunicacional la revitalización de sus costumbres, tradiciones y por ende la conservación de su identidad cultural como pueblo sumu-tuahka, desde las propias voces y cosmovisiónes de cada uno y una de sus habitantes, todos uniendo esfuerzos, enfocados en las prácticas culturales de su pueblo.

Asimismo, pretende llegar a cada uno de los hogares de las familias con la visión de practicar el buen vivir de los pueblos, fomentando su acción participativa desde los distintos niveles y estructuras, sean estas comunitaria, municipales, estatales y la sociedad civil organizada para incidir y crear sensibilidad en la nueva generación y de esta manera revertir las incidencias directas que están causando los medios de comunicación al presentar una vida cultural distinta a la de su pueblo, la cual constituye una de las causas principales de la pérdida de la identidad cultural en los últimos años.

La importancia de la propuesta, radica en la oportunidad que pueden brindar los distintos medios de comunicación a la población indígena de Wasakin al poner en disposición sus medios en los cuales se les dotara de herramientas que permitirán rescatar su cultura en riesgo, fomentando las buenas prácticas tradicionales. 


\section{Lista de referencias}

Acosta, M. L (2004). El derecho de los pueblos indígenas al aprovechamiento Sostenible de sus bosques. Managua, Nicaragua: EDIDARTE.

Asamblea Nacional. (1993). Ley No. 162. Ley de uso oficial de las lenguas de las comunidades de la Costa Atlántica de Nicaragua. Publicada en La Gaceta Diario Oficial No. 132, del 15 de Julio de 1996. Nicaragua.

Ban Ki-moon. (12 de julio, 2013). Los medios de comunicación indígena un aporte a la diversidad cultural. Recuperado en: https://notiindigena.wordpress.com/2013/07/12/ bolivia-medios-de- comunicación-indígenas-un-aporte-a-la-diversidad-cultural/

Conzemius, E. (2004). Miskitos y Sumus de Honduras y Nicaragua (1ra ed.). Managua, Nicaragua: Imprelibros S.A.

Cunningham, L. (2010). Derechos de las Comunidades a su Consentimiento previo sobre la Explotación de los Recursos Naturales en la Costa Caribe de Nicaragua. Revista Wani 63 (32).

Fonseca, G., \& Escribano, P. (2009). Contribuyendo al Uso Sostenible de los Recursos Naturales en dos Territorios Indígenas de la Reserva de Biosfera BOSAWAS. Revista Wani 60 (74).

Gómez, F. (2010). Identidad y desplazamiento lingüístico en la comunidad de Wasakin, municipio de Rosita, R.A.A.N. Ciencia e Interculturalidad 6 (1), $10-25$.

Liceras, A. (2005). Los medios de comunicación de masas, educación informal y aprendizajes sociales. IBER Didáctica de las Ciencias Sociales, Geografía e Historia, 46, 109-124. Recuperado en: http://www.ub.edu/histodidactica/images/documentos/pdf/ medios_comunica cion_masas_educacion_informal_aprendizajes_sociales.pdf

Plaza, F. (2014, 23 de mayo). Globalización y comunicación. Medios para los pueblos, comunicación para la diversidad. Recuperado en: http://comunicacionglobalindigena. blogspot.com/2014_05_01_archive.html

Tornero y Parceval. (s.f). Guía sobre el lenguaje de la televisión y los valores; 100 pregunta y respuestas. UNESCO. Recuperado en: http://www.gabinetecomunicacionyeducacion.com/sites/default/files/field/adj untos/guia_mentor_3.pdf 